\title{
$\checkmark$ Muscle injuries and PRP: cornass crofer what does the science say?
}

\author{
Kimberly G Harmon
}

Muscle strains and contusions are extremely common in sport and account for significant time loss. ${ }^{12}$ The healing process can be slow, and reinjury is common. ${ }^{3}$ Recently there has been significant interest in the use of platelet-rich plasma (PRP) to enhance healing. In this issue, Mei-Dan et al (see page 618) discuss the biological background and clinical rationale for the use of PRP. ${ }^{4}$ This paper will address the use of PRP to enhance the speed and quality of repair in muscle injury.

\section{FIRST PHASE OF HEALING}

When muscle is injured, capillary rupture and bleeding leads to a sequence of highly coordinated events. The first phase is the degeneration/inflammation phase and is characterised by the rupture of myofibrils and their ensuing necrosis. A haematoma forms between the stumps of the ruptured myofibrils, and inflammatory cells invade. ${ }^{3}$ Platelets arrive, adhere to the exposed collagen, become activated and immediately begin to release growth factors and cytokines further amplifying the inflammatory process. Neutrophils begin to migrate to the area and arrive as early as $1-2 \mathrm{~h}$ after injury. ${ }^{5}$

The neutrophils are phagocytic and contain over 40 hydrolytic enzymes. Their activation leads to phagocytosis of debris, and also to the release of oxygen free radicals and proteases. This release of toxic molecules from the neutrophils can lead to secondary damage to the muscle. ${ }^{25} 6$ In fact, the time of peak muscle injury correlates to the time of maximal neutrophil invasion and not to the initial injury. ${ }^{5}$ In models where neutrophils were depleted prior to injury or their respiratory burst blocked, the amount of damage was significantly reduced. ${ }^{78}$ There is debate as to whether or not neutrophils play any type of beneficial role in muscle injury, but it is clear they may be detrimental. ${ }^{125}$

Macrophages follow the neutrophils and have many roles, but do not appear

Correspondence to Dr Kimberly G Harmon, Hall Health Sports Medicine Clinic, Box 354410, University of Washington, Seattle, WA 98195, USA; kharmon@ u.washington.edu to have a role in secondary muscle injury. Macrophages are phagocytic and switch from a proinflammatory type to an antiinflammatory phenotype as the muscle begins to regenerate. ${ }^{2}$ In addition, macrophages prevent muscle cells from undergoing apoptosis and also secrete cytokines and growth factors.

\section{REGENERATIVE PHASE: MAKING NEW MUSCLE}

After a few days, the regenerative phase begins. Satellite cells are activated and produce myoblasts, which eventually fuse with other myoblasts resulting in mature, multinucleated myofibres. ${ }^{1}$ This is the key phase in muscle regeneration. Depending on the growth factor milieu, the satellite cells can be influenced to become either myoblast, which produce muscle cells, or myofibroblasts, which produce fibrotic scar tissue. In particular, insulin-like growth factor 1 (IGF-1) appears to play a critical role in enhancing muscle regeneration by stimulating myoblast proliferation, differentiation and myofibre protein synthesis and hypertrophy. ${ }^{9}$ IGF-1 is found in trivial amounts in platelets, and most IGF-1 in PRP will be present in the original plasma. ${ }^{10}$ Conversely, transforming growth factor $\beta 1$ (TGF $\beta 1$ ) appears to encourage the formation of fibrosis by stimulating the production of extracellular matrix proteins and inhibiting their degradation. ${ }^{11}$

\section{REMODELLING AND FIBROSIS}

In the second week, remodelling begins and involves the maturation of the regenerated myofibres, retraction and reorganisation of the scar tissue and recovery of functional capacity. ${ }^{3}$ Fibrosis is the key inhibitor of complete muscle healing. ${ }^{10}$ The fibrotic tissue provides an early framework for ruptured myofibres. As the fibrous tissue becomes increasingly dense, it restricts the regeneration of the muscle by preventing the stumps of the myofibres from rejoining and may prevent axons from creating new neuromuscular junctions. ${ }^{1} 11$ Fibres that are not innervated will ultimately undergo atrophy.

\section{CAN TREATMENT ACCELERATE MUSCLE HEALING?}

There have been many attempts to speed muscle healing. Traditionally, ice, rest, anti-inflammatory medications and rehabilitation have been the mainstays of treatment. The use of non-steroidal anti-inflammatory drugs (NSAIDs) has been questioned. NSAIDs increase the expression of TGF $\beta 1$ and decrease prostaglandin E2, which has a key role in the proliferation and differentiation of satellite cells. ${ }^{1}$ Recent studies have shown that NSAIDs likely tip the delicate balance of regeneration versus fibrosis toward fibrosis (scar).

In Europe, there is great enthusiasm for a combination of Traumeel S, Actovegin and local anaesthetic which is injected into injured muscle and in the corresponding area of the lumbar spine, despite the fact that there is no good clinical evidence of efficacy and little theoretical scientific basis. This dichotomy of practice and science has been debated by Orchard et a ${ }^{12}$ and McCrory et $a^{13}$ in recent issues of $B J S M$.

With PRP, the growth factors are provided in physiological proportions with the hope this will accelerate healing and lead to a balance of proliferative and inhibitory effects. Although this has theoretical and basic science underpinnings (if perhaps a little simplified) there has been little published quality research on the use of PRP in muscle.

\section{ANIMAL/LABORATORY STUDIES}

PRP has been shown to stimulate cell migration and myofibroblastic differentiation in vitro. ${ }^{14}$ Hammond et al noted increased healing of repetitive muscle injury in rats, but not in those with injury due to a single lengthening contraction. ${ }^{15}$ WrightCarpenter et al found improved healing of muscle injuries in mice with autologous conditioned serum. ${ }^{16}$ Autologous conditioned serum is serum containing released growth factors, essentially activated PRP, which produces a lower yield of growth factors than most PRP.

\section{HUMAN STUDIES}

Studies in human muscle injury are few and of low methodical quality. WrightCarpenter et al treated 18 professional sportsmen with a variety of muscle strains with ACS and reported improved healing by almost a week compared with a similar group of 11 professional athletes. ${ }^{17}$ The numbers in this study are small, the muscle strains are heterogenous, and there was no true 'control' group, as the 'control 
group' had been treated with Traumeel S and Actovegin, and was reviewed, retrospectively. Sanchez reported in a poster presentation a case series of 20 professional athletes with hamstring muscle injuries who received PRP therapy that functional recovery was regained in half the expected time, but we have found no peer-reviewed publication from this poster (Sanchez 2005).

\section{CLINICAL ADVICE: 2010}

Serious questions remain as when and how to use PRP in muscle injury. A muscle is an actively healing, acutely inflammatory entity, and there remains potential to affect both the timing and the quality of repair adversely. PRP is heterogenous, and it may be that certain types of PRP are more effective than others. The timing, quantity and frequency of injections required are also in question. Given the pathophysiology of muscle healing, if PRP is used, the following can be considered:

- PRP should not be administered in the first $24 \mathrm{~h}$ after injury. Attempts should be made to limit the 'secondary injury' using traditional means of controlling inflammation, namely compression, elevation and ice;

- a leucocyte-poor product may mitigate the potentially adverse affects of neutrophils;

- a product which includes a higher proportion of plasma may have increased levels of IGF-1 and potentially enhance healing and decrease fibrosis. ${ }^{10}$

Although acute muscle injuries are typically self-limited and heal if given enough time for recovery, they result in significant morbidity and time lost from competition. There is theory and preliminary evidence regarding the effectiveness of $\mathrm{PRP}$, but its use is still investigational. It is incumbent upon physicians using this treatment to disclose its experimental status and to follow outcomes in a structured way. Further studies are needed to establish the effectiveness, indications and protocols for using PRP in the treatment of acute muscle injuries.

Competing interests None.

Provenance and peer review Not commissioned; not externally peer reviewed.

Accepted 13 April 2010

Br J Sports Med 2010;44:616-617.

doi:10.1136/bjsm.2010.074138

\section{REFERENCES}

1. Prisk V , Huard J. Muscle injuries and repair: the role of prostaglandins and inflammation. Histol Histopathol 2003:18:1243-56.

2. Smith C, Kruger MJ, Smith RM, et al. The inflammatory response to skeletal muscle injury: illuminating complexities. Sports Med 2008;38:947-69.

3. Huard J, Li Y, Fu FH. Muscle injuries and repair: current trends in research. J Bone Joint Surg Am 2002;84-A:822-32.

4. Mei-Dan 0, Mann G, Maffulli N. Platelet-rich plasma: any substance into it? Br J Sports Med 2010:44:618-19.

5. Toumi H, Best TM. The inflammatory response: friend or enemy for muscle injury? Br J Sports Med 2003;37:284-6.
6. Tidball JG. Inflammatory processes in muscle injury and repair. Am J Physiol Regul Integr Comp Physiol 2005:288:R345-53.

7. Brickson S, Ji LL, Schell K, et al. M1/70 attenuates blood-borne neutrophil oxidants, activation, and myofiber damage following stretch injury. J Appl Physiol 2003;95:969-76.

8. Kyriakides C, Austen W Jr, Wang Y, et al. Skeletal muscle reperfusion injury is mediated by neutrophils and the complement membrane attack complex. Am J Physiol 1999;277:C1263-8.

9. Engert JC, Berglund EB, Rosenthal N. Proliferation precedes differentiation in IGF-I-stimulated myogenesis. J Cell Biol 1996;135:431-40.

10. Creaney L, Hamilton B. Growth factor delivery methods in the management of sports injuries: the state of play. Br J Sports Med 2008;42:314-20.

11. Li Y, Huard J. Differentiation of muscle-derived cells into myofibroblasts in injured skeletal muscle. Am J Pathol 2002;161:895-907.

12. Orchard JW, Best TM, Mueller-Wohlfahrt HW, et al. The early management of muscle strains in the elite athlete: best practice in a world with a limited evidence basis. Br J Sports Med 2008;42:158-9.

13. McCrory $\mathbf{P}$, Franklyn-Miller $A$, Etherington J. Sports and exercise medicine - new specialists or snake oil salesmen? Br J Sports Med 2009; (In Press).

14. Menetrey J, Kasemkijwattana C, Day CS, et al. Growth factors improve muscle healing in vivo. $J$ Bone Joint Surg Br 2000;82:131-7.

15. Hammond JW, Hinton RY, Curl LA, et al. Use of autologous platelet-rich plasma to treat muscle strain injuries. Am J Sports Med 2009; 37:1135-42.

16. Wright-Carpenter T, Opolon P, Appell HJ, et al. Treatment of muscle injuries by local administration of autologous conditioned serum: animal experiments using a muscle contusion model. Int J Sports Med 2004:25:582-7.

17. Wright-Carpenter T, Klein P, Schäferhoff $P$, et al. Treatment of muscle injuries by local administration of autologous conditioned serum: a pilot study on sportsmen with muscle strains. Int J Sports Med 2004;25:588-93. 